\title{
Conformational Transition of Styrene-p-Chlorostyrene Triblock Copolymers in Selective Solvents
}

\author{
Etsuyo OGAWA and Mikiko SHIMA \\ Tokyo Woman's Christian University, \\ Zempukuji, Suginami-ku, Tokyo 167, Japan
}

(Received October 14, 1985)

\begin{abstract}
KEY WORDS Conformational Transition / Styrene-p-Chlorostyrene Triblock Copolymers / Selective Solvent / Intrinsic Viscosity / Temperature Dependence /
\end{abstract}

Solution properties of block copolymers have received much attention in recent years. ${ }^{1}$ Two typical conformations have been taken as plausible models to describe the block copolymer conformation; one is a quasi-random coil conformation, and the other is a segregated conformation in which dissimilar segments rarely come in contact so that intramolecular phase separation occurs. ${ }^{1}$ For certain di- or triblock copolymers composed of a pair of incompatible polymers, it is known that a conformational transition from the quasi-random coil to segregated form takes place, depending on the selectivity of the solvent and temperature. $^{1 \mathrm{~b}}$

We previously studied ${ }^{2}$ the temperature dependences of conformational behaviour of styrene (St)-p-chlorostyrene ( $\mathrm{ClSt}$ ) block copolymers of $\mathrm{A}_{m} \mathrm{~B}_{2 n} \mathrm{~A}_{m}$ and $\mathrm{B}_{n} \mathrm{~A}_{2 m} \mathrm{~B}_{n}$ types $(\mathrm{A}, \mathrm{St}$ monomeric unit; $\mathrm{B}, \mathrm{ClSt}$ monomeric unit, $m$ and $n$ denote the number of units) in a selective solvent of cumene which is a good solvent for polystyrene (PSt) but a poor solvent for poly$p$-chlorostyrene (PClSt, $\theta=59.0^{\circ} \mathrm{C}^{3}$ ). In that study, ${ }^{2 \mathrm{c}}$ it was found that the conformational transition from the quasi-random coil to segregated form takes place at higher temperature for the $\mathrm{A}_{m} \mathrm{~B}_{2 n} \mathrm{~A}_{m}$ copolymer than for the $\mathrm{B}_{n} \mathrm{~A}_{2 m} \mathrm{~B}_{n}$ copolymer with the same molecular weight and composition. This means the conformational transition temperature for the triblock copolymer having a long insolublesubchain as the middle block is higher than that for the triblock copolymer having short insoluble-side chains.

In this note, in order to confirm the previous conclusions, the intrinsic viscosities of the $\mathrm{A}_{m} \mathrm{~B}_{2 n} \mathrm{~A}_{m}$ and $\mathrm{B}_{n} \mathrm{~A}_{2 m} \mathrm{~B}_{n}$ copolymers were measured in diisobutyl ketone (DIBK) over a wide temperature range. DIBK is a selective solvent which has a selectivity opposite to cumene; i.e., DIBK is a moderate solvent for PCISt but a poor solvent for PSt $\left(\theta=84.0^{\circ} \mathrm{C}^{4}\right)$.

\section{EXPERIMENTAL}

\section{Materials}

Two samples, an $\mathrm{A}_{m} \mathrm{~B}_{2 n} \mathrm{~A}_{m}$ copolymer and a $\mathrm{B}_{n} \mathrm{~A}_{2 m} \mathrm{~B}_{n}$ copolymer, were prepared by the anionic polymerization technique using sodium naphthalene as the initiator and tetrahydrofuran as the solvent, as described before. $^{2 a}$ The number average molecular weight and composition of these two samples are about the same; for the $\mathrm{A}_{m} \mathrm{~B}_{2 n} \mathrm{~A}_{m}$ copolymer, the number average molecular weight is $58.1 \times 10^{4}$ and the St content in mole fraction, 0.480 ; the corresponding quantities for the 
$\mathrm{B}_{n} \mathrm{~A}_{2 m} \mathrm{~B}_{n}$ copolymer are $55.3 \times 10^{4}$ and 0.515 .

DIBK was purified according to the standard procedure, ${ }^{5}$ and the purity was checked by means of gas chromatography.

\section{Measurements}

Viscosities of the block copolymer solutions were measured over the temperature range from 65 to $20^{\circ} \mathrm{C}$ by Ubbelohde dilution viscometers with negligible kinetic energy corrections. Plots of $\eta_{\mathrm{sp}} / c v s$. $c$ were extrapolated to zero concentration to obtain intrinsic viscosities $[\eta]$ according to Huggins' equation ${ }^{6}$ :

$$
\eta_{\mathrm{sp}} / c=[\eta]+k_{\mathrm{H}}[\eta]^{2} c+\cdots
$$

in which $\eta_{\mathrm{sp}}$ is the specific viscosity and $k_{\mathrm{H}}$ is Huggins' constant. The concentration $c$ of the solutions used for measurements was in the range of 0.15 to $0.5 \mathrm{~g} \mathrm{dl}^{-1}$. The St-ClSt block copolymers are not very stable in DIBK. It was observed that the flow times slightly decreased after keeping the solution at $55^{\circ} \mathrm{C}$ for two hours, which should be due to degradation of the copolymer. Therefore, viscosities were measured with caution so as not to leave the solution long when the temperature was elevated. All the values of $[\eta]$ obtained showed good reproducibility.

\section{RESULTS AND DISCUSSION}

The intrinsic viscosities for the $\mathrm{B}_{n} \mathrm{~A}_{2 m} \mathrm{~B}_{n}$ and $\mathrm{A}_{m} \mathrm{~B}_{2 n} \mathrm{~A}_{m}$ copolymers in DIBK are plotted as functions of temperature in Figure 1. On lowering the temperature, the solution of the highest concentration ( $c a .0 .5 \mathrm{~g} \mathrm{dl}^{-1}$ ) used for viscometry became somewhat turbid at $40^{\circ} \mathrm{C}$ for the $\mathrm{B}_{n} \mathrm{~A}_{2 m} \mathrm{~B}_{n}$ copolymer and below $35^{\circ} \mathrm{C}$ for the $\mathrm{A}_{m} \mathrm{~B}_{2 n} \mathrm{~A}_{m}$ copolymer, but the solutions of lower concentration remained clear down to a much lower temperature, until $30^{\circ} \mathrm{C}$ for the $\mathrm{B}_{n} \mathrm{~A}_{2 m} \mathrm{~B}_{n}$ copolymer and $20^{\circ} \mathrm{C}$ for the $\mathrm{A}_{m} \mathrm{~B}_{2 n} \mathrm{~A}_{m}$ copolymer. The filled circles and triangles in Figure 1 indicate that the solutions of the highest concentration are somewhat turbid. It is likely that intermolecular association took

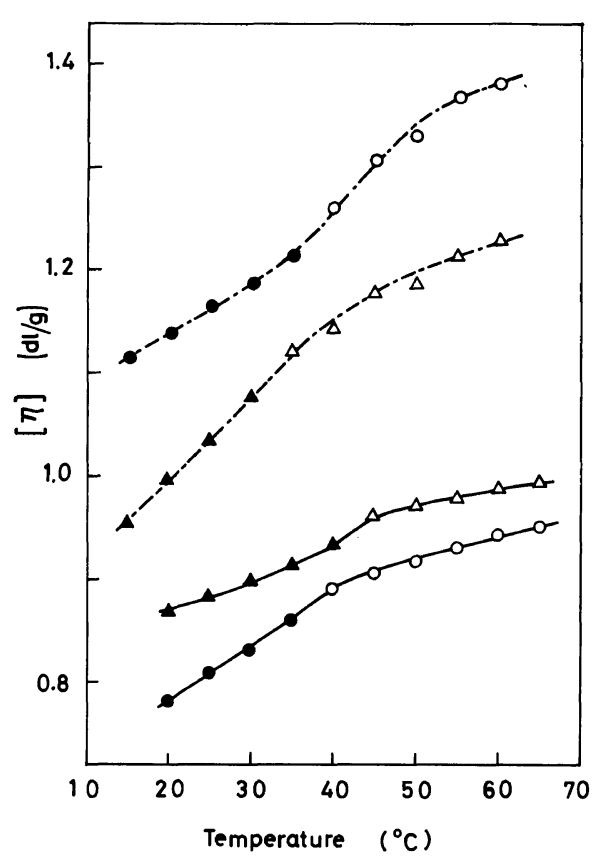

Figure 1. Temperature dependence of the intrinsic viscosities of the St-CISt triblock copolymers in DIBK and in cumene: (○), $A_{m} B_{2 n} A_{m}$ copolymer; $(\triangle), B_{n} A_{2 m} B_{n}$ copolymer; $(-)$, in DIBK; (-- - ), in cumene.

place in the block copolymer solutions which seemed somewhat turbid. However, the extent of the association should be very small under the conditions of the present experiments except for the $\mathrm{B}_{n} \mathrm{~A}_{2 m} \mathrm{~B}_{n}$ copolymer solutions below $30^{\circ} \mathrm{C}$, since a plot of $\eta_{\mathrm{sp}} / c v s . c$ for the solution in question showed no significant deviation from the linear relationship of $\eta_{\mathrm{sp}} / c$ $v s$. $c$ obtained for the solutions of lower concentrations. All the values of $[\eta]$ obtained in the measurements showed good reproducibility. Variation of $[\eta]$ with temperature should be interpreted as a reflection of conformational change of the copolymer molecules. It was observed that in DIBK, the $[\eta]$ values for the $\mathrm{B}_{n} \mathrm{~A}_{2 m} \mathrm{~B}_{n}$ copolymer were always larger than those for the $A_{m} B_{2 n} A_{m}$ copolymer, which implies that the $\mathrm{B}_{n} \mathrm{~A}_{2 m} \mathrm{~B}_{n}$ copolymer takes a more extended conformation than the $\mathrm{A}_{m} \mathrm{~B}_{2 n} \mathrm{~A}_{m}$ copolymer. On the other hand, viscosity data ${ }^{2 c}$ previously obtained on the same copolymer 
samples in cumene showed that the $\mathrm{A}_{m} \mathrm{~B}_{2 n} \mathrm{~A}_{m}$ copolymer takes a more extended conformation than the $\mathrm{B}_{n} \mathrm{~A}_{2 m} \mathrm{~B}_{n}$ copolymer, which are also given in Figure 1 for the purpose of comparison.

By lowering the temperature, the $[\eta]$ for the block copolymers in DIBK decreased gradually, but variation of $[\eta]$ with temperature was not uniform; $[\eta]$ changed markedly from a slow to fast decrease at a critical point which appears to be around $45^{\circ} \mathrm{C}$ for the $\mathrm{B}_{n} \mathrm{~A}_{2 m} \mathrm{~B}_{n}$ copolymer and around $40^{\circ} \mathrm{C}$ for the $\mathrm{A}_{m} \mathrm{~B}_{2 n} \mathrm{~A}_{m}$ copolymer. This trend is the same as previously observed in $[\eta] v s$. temperature curves obtained for these block copolymers in cumene. ${ }^{2 \mathrm{c}}$ It is hard to draw a conclusion about the conformational transition of the block copolymers only from the result described above. However, previous studies ${ }^{2 \mathrm{c}}$ on osmotic second virial coefficient and light scattering of the $\mathrm{B}_{n} \mathrm{~A}_{2 m} \mathrm{~B}_{n}$ and $\mathrm{A}_{m} \mathrm{~B}_{2 n} \mathrm{~A}_{m}$ copolymers in cumene led to the conclusion that the conformational transition from the quasi-random coil to segregated form occurs at a temperature where variation of $[\eta]$ with temperature changed markedly from a slow to fast decrease. Since a general feature of the shape of $[\eta] v s$. temperature curves is common to those obtained in DIBK and in cumene, it is believed that the marked change of $[\eta]$ around $45^{\circ} \mathrm{C}$ for the $\mathrm{B}_{n} \mathrm{~A}_{2 m} \mathrm{~B}_{n}$ copolymer and around $40^{\circ} \mathrm{C}$ for the $\mathrm{A}_{m} \mathrm{~B}_{2 n} \mathrm{~A}_{m}$ copolymer corresponds to the conformational transition in DIBK. Consequently, from the $[\eta]$ data in this study, it can be concluded that the conformational transition occurs at higher temperature for the $\mathrm{B}_{n} \mathrm{~A}_{2 m} \mathrm{~B}_{n}$ copolymer than for the $A_{m} B_{2 n} A_{m}$ copolymer in DIBK. This result obtained in DIBK is in contrast with that in cumene, and it gives positive support to our previous conclusion that the conformational transition temperature for the triblock copolymer having a long insoluble-subchain as the middle block is higher than that for the triblock copolymer in which short insoluble-side chains attach to the middle soluble block. It is expected that this conclusion is applicable to all other triblock copolymers in selective solvents.

Some comments are should be made with regard to differences between the shape of $[\eta]$ $v s$. temperature curve for the $\mathrm{B}_{n} \mathrm{~A}_{2 m} \mathrm{~B}_{n}$ copolymer and that for the $\mathrm{A}_{m} \mathrm{~B}_{2 n} \mathrm{~A}_{m}$ copolymer in the region of low temperature. Below the transition temperature in DIBK, a decrease of $[\eta]$ with temperature was linear and uniform for the $\mathrm{A}_{m} \mathrm{~B}_{2 n} \mathrm{~A}_{m}$ copolymer but not for the $\mathrm{B}_{n} \mathrm{~A}_{2 m} \mathrm{~B}_{n}$ copolymer. The $[\eta] v s$. temperature curve for the $\mathrm{B}_{n} \mathrm{~A}_{2 m} \mathrm{~B}_{n}$ copolymer showed the second transition around $30^{\circ} \mathrm{C}$. The values of $[\eta]$ for the $\mathrm{B}_{n} \mathrm{~A}_{2 m} \mathrm{~B}_{n}$ copolymer solutions in the region below $30^{\circ} \mathrm{C}$ may be associated with the formation of intermolecular aggregates.

\section{REFERENCES}

1. (a) J. V. Dawkins, "Block Copolymers," D. C Allport and W. H. Janes, Ed., Applied Science, London, 1973, Chapter 9; (b) J. M. G. Cowie, "Developments in Block Copolymers," I. Goodman, Ed., Applied Science, London, 1982, Chapter 1.

2. (a) M. Shima, E. Ogawa, and K. Konishi, Makromol. Chem., 177, 241 (1976); (b) M. Shima, E. Ogawa, S. Ban, and M. Sato, J. Polym. Sci., Polym. Phys. Ed., 15, 1999 (1977); (c) M. Shima, E. Ogawa, and M. Sato, Polymer, 20, 311 (1979); (d) M. Shima, N. Yamaguchi, M. Sato, and E. Ogawa, Eur. Polym. J., 19, 601 (1983).

3. Y. Izumi and Y. Miyake, Polym. J., 4, 205 (1973).

4. F. Horii, Y. Ikada, and I. Sakurada, J. Polym. Sci., Polym. Chem. Ed., 12, 323 (1974).

5. J. A. Riddick and W. B. Bunger, "Organic Solvents," Wiley-Interscience, New York, N. Y., 1970.

6. M. L. Huggins, J. Am. Chem. Soc., 64, 2716 (1942). 